\section{A Wider Approach to Obstructive Sleep Apnea in Primary Health Care}

Uma Abordagem Mais Ampla da Apneia Obstrutiva do Sono nos Cuidados de Saúde Primários

Keywords: Obesity; Portugal; Primary Health Care; Sleep Apnea, Obstructive/diagnosis; Surveys and Questionnaires

Palavras-chave: Apneia Obstrutiva do Sono/diagnóstico; Cuidados de Saúde Primários; Inquéritos e Questionários; Obesidade; Portugal

Dear editor, I was very pleased to read your article on such an important matter, entitled as "Undiagnosed Risk of Obstructive Sleep Apnea in Obese Individuals in a Primary Health Care Context". ${ }^{1}$ It highlights the need to increase awareness of family physicians to this problem and the use of appropriate evaluation tools as this disorder increases morbidity and mortality rates.

However, as only briefly mentioned in the article, obstructive sleep apnea (OSA) is not exclusively related with obesity. There are other risk factors that are associated with this disorder that one should keep in mind, such as male gender, advanced age (especially the sixth and seventh decades) and craniofacial or upper airway abnormalities. Also, it seems that post-menopausal women have a higher risk of developing OSA compared to other women, reaching similar rates as males with the same age.

The presence of these risk factors combined with sus- picious symptoms of OSA (excessive daytime sleepiness, snoring, and gasping or choking during sleep) should prompt the use of appropriated evaluations tools (like the Enhanced Version of Stop-BANG questionnaire or the Epworth Sleepiness scale) in order to select those who need referral to Secondary Care to continue the diagnostic approach.

Furthermore, this cross-sectional study used the Stop-BANG questionnaire by Chung et $a l,{ }^{2}$ but there are other evaluation tools that can be more useful, like the Enhanced Version of the STOP-Bang questionnaire described by Chung in $2016,{ }^{3}$ where patients who were initially as having intermediate risk of OSA can be further stratified if they also scored positive for one of the following parameters: body mass index above $35 \mathrm{~kg} / \mathrm{m}^{2}$, neck circumference above $43 \mathrm{~cm}$ in males and $41 \mathrm{~cm}$ in females.

Moreover, there are other screening tools like the Epworth Sleepiness scale (ESS), ${ }^{4}$ that is validated for the Portuguese population, and others which require more studies and validation, like the Lausanne NoSAS (Neck circumference, Obesity, Snoring, Age, and Sex $)^{5}$ which seems to be a promising method for stratifying and prioritizing patients with a diagnosis of OSA in Primary Health Care.

Despite these different screening methods, we must not forget that polysomnography is the gold standard diagnostic test and family physicians should always have a preemptive approach by reducing the number of OSA cases which remain underdiagnosed and allowing for prompt treatment.

\title{
REFERENCES
}

1. Ribeiro JP, Araújo A, Vieira C, Vasconcelos F, Pinto PM, Seixas B, et al. Undiagnosed risk of obstructive sleep apnea in obese individuals in a Primary Health Care context. Acta Med Port 2020;33:161-5.

2. Chung F, Yegneswaran B, Liao P, Chung SA, Vairavanathan S, Islam S, et al. STOP questionnaire: a tool to screen patients for obstructive sleep apnea. Anesthesiology. 2008;108:812-20.

3. Chung F, Abdullah HR, Liao P. STOP-Bang questionnaire: a practical

approach to screen for obstructive sleep apnea. Chest. 2016;149:631-8.

4. Bodkin CL, Manchanda S. Office evaluation of the "tired" or "sleepy" patient. Semin Neurol. 2011;31:42-53.

5. Costa J, Rebelo-Marques A, Machado J, et al. Validation of NoSAS (Neck, Obesity, Snoring, Age, Sex) score as a screening tool for obstructive sleep apnea: analysis in a sleep clinic. Pulmonology. 2019;25:263-70.

Catarina BAÍA $\otimes^{1}$, Isabel Ralha de ABREU1

1. Unidade de Saúde Familiar St. André de Canidelo. Agrupamento de Centros de Saúde Grande Porto VII Gaia. Administração Regional da Saúde Norte. Vila Nova de Gaia. Portugal. Autor correspondente: Catarina Baía. catarinabaiaantunes@gmail.com

Recebido: 20 de março de 2020 - Aceite: 23 de março de 2020 | Copyright $\odot$ Ordem dos Médicos 2020 https://doi.org/10.20344/amp.13745

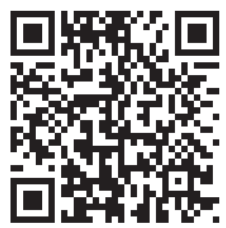

